DEMOGRAPHIC RESEARCH

VOLUME 43, ARTICLE 5, PAGES 129-142

PUBLISHED 24 JULY 2020

http://www.demographic-research.org/Volumes/Vol43/5/

DOI: 10.4054/DemRes.2020.43.5

Summary

\title{
Introduction to the special collection on life course decisions of families in China
}

\section{Bing Xu}

\section{William A.V. Clark}

\section{Eric Fong}

\section{Li Gan}

This publication is part of the Special Collection on Life-Course Decisions of Families in China, organized by Guest Editors Bing Xu, William A.V. Clark, Eric Fong, and Li Gan.

(C) 2020 Bing Xu, William A.V. Clark, Eric Fong, Li Gan.

This open-access work is published under the terms of the Creative Commons Attribution 3.0 Germany (CC BY 3.0 DE), which permits use, reproduction, and distribution in any medium, provided the original author(s) and source are given credit.

See https://creativecommons.org/licenses/by/3.0/de/legalcode. 


\section{Contents}

$\begin{array}{lll}1 & 130\end{array}$

2 Contents of the Special Collection 132

$3 \quad$ Conclusion and avenues for further research 134

4 Acknowledgements 136

$\begin{array}{ll}\text { References } & 137\end{array}$ 


\title{
Introduction to the special collection on life course decisions of families in China
}

\author{
Bing $\mathrm{Xu}^{1}$ \\ William A.V. Clark ${ }^{2}$ \\ Eric Fong ${ }^{3}$ \\ Li Gan ${ }^{4}$
}

\begin{abstract}
BACKGROUND

The economic reforms of the last thirty years have produced a dramatic improvement in the standard of living in China. However, the concurrent social transformation has also created both stresses and challenges for Chinese families. While researchers have paid considerable attention to the headline demographic statistics accompanying these economic and social transformations, the nuanced ways in which Chinese society has changed and continues to change since the reforms are less understood.
\end{abstract}

\section{CONTRIBUTION}

This special collection uses the life course framework, which has emerged as an important organizing concept within demographic studies, to examine constancy and change in Chinese society since the reforms of the late 1990s. By framing life events as the result of decisions that are influenced by and sometimes are direct responses to China's modernization, and investigating how these decisions collectively affect and reshape Chinese society, the papers in this collection provide a rich way of interpreting and understanding demographic changes in China.

\footnotetext{
${ }^{1}$ Southwestern University of Finance and Economics, Chengdu, China. Email: xubing@swufe.edu.cn.

${ }^{2}$ University of California, Los Angeles, USA.

${ }^{3}$ University of Hong Kong, Hong Kong, SAR, China.

${ }^{4}$ Texas A\&M University, College Station, USA.
} 


\section{Introduction}

The rapid modernization and development of the last thirty years have had a profound effect on Chinese society. While economic reforms have produced dramatic improvements in the standard of living in China, the concurrent social transformation has created both stresses and challenges for its families, long regarded as the bedrock of Chinese society. The current generation of Chinese enjoy higher wealth, increased life expectancy, better education, greater mobility, and expanded opportunities; however, they also face widening income and wealth inequalities, rapidly rising house prices, and intensifying competition in education and employment. The headline demographic trends accompanying these economic and social transformations, such as declining fertility rates, a persistent gender imbalance, and aging of the population, have received considerable attention from researchers and much is known. Yet, less understood are the nuanced ways in which Chinese society has changed and is continuing to change since the reforms of the late 1990s. The papers in this special collection address these changes within a life course framework, which has become a core conceptual structure for studying our changing societies and the individuals in them.

Despite a somewhat amorphous and disparate approach to the life course, and even calls for greater clarity in its modeling, at its heart the life course perspective is about taking a long view and examining multiple life domains and multiple levels of analysis (Bernardi, Huinink, and Setterston 2019). Building upon earlier concepts of the life course given in Elder and O'Rand (1995) and Giele and Elder (1998), Bernardi and colleagues define the life course as a multifaceted process of individual behavior that evolves from the steady flow of individuals' actions and experiences and modifies their biographical state. Thus, a central element of life course analysis from a demographic perspective is the role of life events - sometimes referred to as triggers (Clark and Dieleman 1996) - that alter the life course path. Several papers in this collection illustrate such categorical events within the life course, while others evaluate the sequence of parallel events which follow categorical choices.

Since the economic reform, life in China has undergone tremendous changes, including increasing divorce rates, declining birthrates, population aging, and rapid urbanization. The life course theory helps connect how different cohorts face and respond to these changes. As such, the papers in this collection frame life events as the result of decisions that are influenced by and sometimes are even direct responses to China's modernization, and investigate how these decisions in turn collectively affect and reshape Chinese society. Using the life course to understand Chinese society and its economy is not new. Since the 1990s researchers have been applying life course perspectives to explore various economic and social patterns in China. Although it did not specifically use life course terminology, Gold's (1990) work is an early study on the 
emergence of private businesses at the beginning of China's economic reform. The study focuses on the early stages of labor market careers when individuals worked in private businesses while waiting for a job assignment after completing education or returning to cities from the countryside after the 'Down to the Countryside Movement.' In his study of changes in Chinese families between 1950 and 1970, Zeng (1991) applies a life course perspective to understand how different age groups are associated with different family dynamics. He shows that there are distinct cohort differences with respect to family size. The research on China using a life course perspective increased in the 1990s, including an exploration of the cohort of children of the cultural revolution (Zhou and Hou 1999), stratification patterns (Zhou, Tuma, and Moen 1996), and living arrangements (Treas and Chen 2000). Since 2000 the life course perspective has flourished and has been applied to diverse topics, including residential mobility (Li 2004), unemployment (Hung and Chiu 2003), and smoking behavior (Kenkel, Lillard, and Liu 2009). However, with the recent, major societal development in China, three areas are particularly timely and deserve more attention: the growing parental investment in children's education in a rapidly increasing competitive educational system, the effect on children's wellbeing of millions of parents deciding to migrate from rural areas to cities, and intergenerational coresidence patterns as the size of the country's senior population rapidly increases.

In summary, and as we illustrate across the papers in this collection, the life course is a conceptual structure that we use to organize the evolving process of decisionmaking and actions regarding a whole raft of life events. At any given moment these big life events intertwine and overlap in a complex web of ties across generations and domains and provide links through which individuals' decisions affect each other. Our collection examines both constancy and change in the entry into partnership, the effect of childhood education on life course success, how migration affects children in a changing labor market, and the connection between adult children and their aging parents. Because these links cannot be separated neatly into a strict purview of demography, economics, or sociology, the collection presents contributions from scholars in all three fields. This is not merely a collection of independent works by demographers, economists, and sociologists on a single topic: The work presented here stems from a conference held in Chengdu, China in 2019 to bring together researchers from all three fields to study household decisions, and is the result of ensuing discussions and cross-field reviews of the findings. As such, the collection represents true interdisciplinary collaboration. 


\section{Contents of the Special Collection}

Although the past 30 years have brought significant changes to the structure of the Chinese family, increasing cohabitation and divorce (Xie 2013; Yu and Xie 2015), the extent to which the Chinese family structure has 'modernized' has remained unclear. For example, scholars have noted that the extended family continues to play a critical role during childrearing and that a large proportion of the elderly still expect - or at least prefer - to live with their children (Chu and $\mathrm{Yu}$ 2010). The first paper in this collection, by Clark and Yi (2020), closely examines recent household data and reveals that China remains relatively traditional, with marriage being nearly universal and family formation occurring rapidly and consistently across both urban and rural areas. Clark and Yi's work suggests that despite the ongoing social and economic transformations, families have endured as the cornerstone of Chinese social structure. Against this backdrop, the remaining articles in the collection delve deeper into different life course aspects of intergenerational family decisions.

The two papers that follow, by Zhou et al. (2020) and Shi, Xu, and Wei (2020), examine parents' investment in their children's education, which is one of the most important ways in which parents prepare children for adulthood (Allat 1993; Bourdieuand and Passeron 1977; Martens, Southerton, and Scott 2004). A number of works have shown that despite the government's effort to reduce urban-rural inequality in China, large gaps in education and health conditions remain ( $\mathrm{Li}$ et al. 2018; Liu et al. 2017; Nie et al. 2020; Wang et al. 2018). The findings of Zhou et al. and Shi, Xu, and Wei exemplify the extent of such urban-rural disparity. In particular, Zhou et al. give a troubling picture of China's rural families, where parents love their children and have high aspirations for them, but despite their willingness to "do anything" for their children, their limited parenting skills and lack of knowledge about childhood development result in low investment in early education. The authors predict that the resulting deficiency in early cognitive development will persist throughout the children's lives, not only trapping the children in poverty in their personal lives but also leading to greater inequality and slower economic growth at the societal level (Heckman and Masterov 2007; Heckman et al. 2010). In sharp contrast, the paper by $\mathrm{Shi}, \mathrm{Xu}$, and Wei examines the recently emerging trend of (mostly urban) parents spending on private education to prepare their children for the college admission process. While previous studies on educational investment have focused on the positive relationship between parents' socioeconomic status and investments in their children (Acemoglu and Pischke 2001; Carneiro and Heckman 2002; Loken 2010), Shi, Xu, and Wei explore the life course effect on parents' investment behavior. They find that parents' investments in their children are positively related to their age at the children's births but are negatively related to their current age, even after controlling for parents' 
socioeconomic characteristics and children's school-stage needs. The first finding suggests that in addition to the biological channel, financial constraints may be another channel through which having a child at a later age limits total fertility, and the second suggests that this channel may strengthen over time.

The next two papers, by Liang and Sun (2020) and Zhan, Zhang, and Lu (2020), study the indirect effects on children of parents' decision to migrate from two different viewpoints. Liang and Sun investigate the effect on children whose migrating parents left them behind, while Zhan, Zhang, and Lu focus on those who moved with their parents. Previous works have been inconclusive as to the effects of being left behind. Some scholars find no systematic effects (Ren and Treiman 2016; Xu and Xie 2015), while others find negative effects on education ( $\mathrm{Lu}$ 2012; Meng and Yamauchi 2017; Zhang et al. 2014), physical health (Meng and Yamauchi 2017; Tong, Luo, and Piotrowski 2015), and mental health (Wen and Lin 2011). Unlike those studies, which examined short-term effects, Liang and Sun's study is one of the first to examine the long-term effect of the left-behind experience. They conclude that being left behind, especially during the primary school years, has substantial negative consequences for the children's long-term education attainment. They also document poor self-reported health and elevated mental health problems during adulthood. By contrast, Zhan, Zhang, and $\mathrm{Lu}$ examine children who moved with their parents during the 1994 poverty-alleviation program that resettled families from 19 poor, mountainous villages of Boshan District, Shandong Province, to comparatively richer suburban areas of Boshan. Like the earlier works on left-behind children, studies on the effects of similar resettlement programs have yielded mixed results. Investigations on the effects of the Moving to Opportunity experiment in the United States and the public housing demolition program in Chicago find some positive long-run economic effects on children who were relocated (Chetty, Hendren, and Katz 2016; Chyn 2018; Jacob 2004). However, using data from an Indonesian government-sponsored transmigration program, Bazzi et al. (2016) argue that gains from a resettlement program depend on the productivity differences and the skills match between the locations involved. Zhan, Zhang, and Lu's study on the Boshan program also shows that benefits of relocating from poor to richer areas may not be universal. In particular, the authors conclude that the resettlement led to lower education attainment for girls while benefiting boys. Moreover, despite migrating to richer areas, the long-term effects of the resettlement on labor market outcomes are negative, as measured by income and occupation choice in adulthood.

After imposing decades of strict family planning, China now faces the challenge of an aging population (Du 2013; Wang, Huang, and Yang 2019), and how best to support aging parents and cope with increased physical distance between the extended family members is becoming a pressing issue for both the families themselves and 
policymakers. The final two papers in this collection, Qin et al. (2020) and Gan and Fong (2020), provide valuable insights into this issue, but from different angles. The papers address the limitations of earlier studies on the subject by including a wider age group of children and employing a recently collected national survey. Qin et al. investigate how the socioeconomic changes have affected the current midlifers' expectation of and preference for providing their own support when they age. The authors conclude that while there is some heterogeneity according to family structure, socioeconomic status, current pattern of intergenerational support, gender, and cohort, an increasing number of Chinese midlifers prefer to live 'independently' in the community. Thus, their preferences increasingly resemble those of their U.S. and European counterparts, who also want to stay in their own home and ease the burden on their children (Cai et al. 2012; Whyte 2012). Rather than focusing on future preferences, Gan and Fong investigate how Chinese families have coped with eldercare challenges by examining the current living arrangements of midlifers in relation to their parents. Unlike previous studies on the subject, Gan and Fong's work is from the viewpoint of the adult children, which allows them to better tease out possible motives for coresidence, such as practical considerations like childcare and high housing prices or traditional values like filial piety and family responsibility (Chu and $\mathrm{Yu}$ 2010). Gan and Fong find that although these motives remain for some midlifers, the overall likelihood of coresiding with aging parents is low compared to 20 years ago. Both Qin et al. and Gan and Fong's findings suggest that the modern trend of greater independence between generations is taking hold in China.

\section{Conclusion and avenues for further research}

The papers in this collection examine how the life course of Chinese households has evolved during the past thirty years. The findings are at first surprising in that they show that despite the rapidly modernizing economy, many of the traditional attitudes and ties remain. The papers paint a picture of a society that is evolving slowly like a gently coursing river, while beneath lie swirls and eddies where traditions run into forces of modernization, and families adapt and change and make household decisions in response to increasing living standards, urbanization, mobility, and competitive pressures. These findings also yield important questions that warrant further investigation.

Clark and Yi (2020)'s study, which shows both continuity and change in the current attitude toward family formation as well as the actual formation patterns, naturally raises a question about the link between attitude and observed behavior. For example, it would be interesting to see if the surveyed individuals whose primary 
reason for marriage was romantic rather than raising a child are more likely to delay marriage or not have any children. Given that the primary reason for marriage for about half of the respondents in the 1990-1994 birth cohort in their study was romantic life, and raising a child the reason for less than $15 \%$, knowing how tight the link between attitude and behavior is may give us a better understanding of developing trends in marriage and fertility. Moreover, if attitudes and behaviors differ, then investigating the factors that make them diverge would be equally important.

The papers by Zhou et al. (2020) and Shi, Xu, and Wei (2020) examine parents' investment in children's education in rural and urban areas, respectively. Their findings suggest that the quantity-quality tradeoff between number of children and each child's human capital development (Becker 1960; Becker and Lewis 1973) may be playing out in different ways in rural and urban China, with the tradeoff resolving in favor of quantity in the rural areas and quality in the urban areas. The rapid urbanization of China means that rural and urban children have a high likelihood of engaging in the same labor market later in their life course. To better understand its possible consequences, such as widening inequality and reduced social mobility, and to implement appropriate public policies now to mitigate them, it is crucial to learn more about the gap between these two groups of children, especially in terms of education and health.

For the millions of rural workers who migrate to cities for work, a vexing question has been whether to bring their school-age children with them to the cities, where they have limited access to education, or to leave them behind in the rural areas. While the works by Liang and Sun (2020) and Zhan, Zhang, and Lu (2020) shed additional light on this issue, data availability has limited their findings in one important aspect. The comparison group in their studies comprises children of families that did not migrate. To better answer the question, a direct comparison is needed between the children who were left behind and those who migrated with their parents. If a conclusive finding can be made from such a comparison, policymakers can incentivize migrant workers to make a better decision, either by improving access to quality education for migrant children in urban areas or by providing better educational resources and other support for the left-behind children in rural areas.

Finally, just as Clark and Yi's (2020) work raises a question about the link between attitude and observed behavior, Qin et al. (2020) and Gan and Fong (2020)'s works on elderly support and living arrangement raise the question of how well expectations and reality match, especially in rural areas. For example, Qin et al. find that current midlifers with rural hukou (household registration) are much more likely to expect to live with their children during their elderly years. However, since Gan and Fong show that one important reason that adult children in urban areas live with their parents is high housing prices, rural adult children, who do not face the same housing 
constraint as their urban counterparts, may be less likely to live with their parents. Moreover, if rural-to-urban migration continues, a large number of rural adults will not be living near their elderly parents, let alone coresiding with them. Given the low level of publicly funded eldercare provision in rural areas, it is important to examine the welfare of such left-behind parents and explore policy options that can improve the rural eldercare system.

As a whole, this special collection not only provides a timely insight into the life course decisions of Chinese families but also generates a fascinating set of new research questions that will contribute to a deeper understanding of Chinese families. As the collection illustrates, the life course approach is a fruitful way to organize and structure research on China's changing society. Longitudinal studies are critical in tracing the paths of change and the implications of those changes for the continuing evolution of a complex and multifaceted society.

\section{Acknowledgements}

We are grateful for helpful suggestions from the participants at the conference on Lifecycle Decisions of Families in China, in Chengdu, May 2019, and the support from the Chinese Ministry of Technology's 111 Project \#B16040 for making the conference possible. We would also like to thank Jakub Bijak and Jana Tetzlaff for their valuable suggestions and guidance in completing this special collection. Bing Xu gratefully acknowledges support from China National Natural Science Foundation grants \#71874144. 


\section{References}

Acemoglu, D. and Pischke, J.S. (2001). Changes in the wage structure, family income, and children's education. European Economic Review 45(4-6): 890-904. doi:10.1016/S0014-2921(01)00115-5.

Allat, P. (1993). Becoming privileged. In: Bates, I. and Riseborough, G. (eds.). Youth and inequality. Milton Keynes: Open University Press: 139-159.

Bazzi, S., Gaduh, A., Rothenberg, A.D., and Wong, M. (2016). Skill transferability, migration, and development: Evidence from population resettlement in Indonesia. American Economic Review 106(9): 2658-2698. doi:10.1257/aer. 20141781.

Becker, G. (1960). An economic analysis of fertility. In: Universities-National Bureau (ed.). Demographic and economic change in developed countries. Princeton: Princeton University Press.

Becker, G. and Lewis, H. G. (1973). On the interaction between the quantity and quality of children. Journal of Political Economy 81(2): S279-S288. doi:10.1086/ 260166.

Bernardi, L., Huinink, J., and Settersten, R. (2019). The life course cube: A tool for studying lives. Advances in Life Course Research 41: 100258. doi:10.1016/ j.alcr.2018.11.004.

Bourdieu, P. and Passeron, J. (1977). Reproduction in education, society and culture. London: Sage.

Cai, F., Giles, J., O'Keefe, P., and Wang, D. (2012). The elderly and old age support in rural China: Challenges and prospects. Washington D.C.: The World Bank.

Carneiro, P. and Heckman, J. (2002). The evidence on credit constraints in postsecondary schooling. The Economic Journal 112(October): 705-734. doi:10.33 86/w9055.

Chetty, R., Hendren, N., and Katz, L.F. (2016). The effects of exposure to better neighborhoods on children: New evidence from the moving to opportunity experiment. American Economic Review 106(4): 855-902. doi:10.1257/aer. 20150572.

Chu, C.Y.C. and Yu, R. (2010). Understanding Chinese families: A comparative study of Taiwan and Southeast China. Oxford: Oxford University Press. 
Chyn, E. (2018). Moved to opportunity: The long-run effects of public housing demolition on children. American Economic Review 108(10): 3028-3056. doi:10.1257/aer.20161352.

Clark, W.A.V. and Dieleman, F. (1996). Households and housing: Choice and outcomes in the housing market. New Brunswick, NJ: Center for Housing Policy Research.

Clark, W.A.V. and Yi, D. (2020). Transitions to partnering and transitions to families: Is China still traditional? Demographic Research 43(6): 143-168. doi:10.4054/DemRes.2020.43.6.

Du, P. (2013). Intergenerational solidarity and old-age support for the social inclusion of elders in Mainland China: The changing roles of family and government. Ageing and Society 33(01): 44-63. doi:10.1017/S0144686X12000773.

Elder, G.H., Jr. and O'Rand, A. (1995). Adult lives in a changing society. In Cook, K.S., Fine, G.A., and House, J.S. (eds.). Sociological perspectives in social psychology. Boston: Allyn and Bacon. 452-475.

Gan, Y. and Fong, E. (2020). Living separate but living close: Co-residence of adult children and parents in urban China. Demographic Research 43(12): 315-328. doi:10.4054/DemRes.2020.43.12.

Giele, J. and Elder, G.H., Jr. (eds.). (1998). Methods of life course research: Qualitative and quantitative approaches. Cambridge: Cambridge University Press. doi:10.4135/9781483348919.

Gold, T. (1990). Urban private business and social change. In Davis, D. and Vogel, E.F. (eds.). Chinese society on the Eve of Tiananmen: The impact of reform. Cambridge, MA: Council on East Asian Studies.

Heckman, J. and Masterov, D.V. (2007). The productivity argument for investing in young children. Applied Economic Perspectives and Policy 29(3): 446-493. doi:10.3386/w13016.

Heckman, J., Moon, S., Pinto, R., Savelyev, P.A., and Yavitz, A. (2010). The rate of return to the HighScope Perry Preschool Program. Journal of Public Economics 94(1-2): 114-128. doi:10.1016/j.jpubeco.2009.11.001.

Hung, E.P.W. and Chiu S.W.K. (2003). The lost generation: Life course dynamics and Xiagang in China. Modern China 29(2): 204-236. doi:10.1177/00977004022 50740 . 
Jacob, B.A. (2004). Public housing, housing vouchers, and student achievement: Evidence from public housing demolitions in Chicago. American Economic Review 94(1): 233-258. doi:10.1257/000282804322970788.

Kenkel, D., Lillard, D.R., and Liu, F. (2009). An analysis of life-course smoking behavior in China. Health Economics 18(S2): S147-S156. doi:10.1002/hec. 1507.

Li, L., Huang, L., Shi, Y., Luo, R., Yang, M., and Rozelle, S. (2018). Anemia and student's educational performance in rural Central China: Prevalence, correlates and impacts. China Economic Review 51: 283-293. doi:10.1016/j.chieco.2017. 07.006 .

Li, S-M. (2004). Life course and residential mobility in Beijing, China. Environment and Planning A: Economy and Space 36(1): 27-43. doi:10.1068/a35243.

Liang, Z. and Sun, F. (2020). The lasting impact of parental migration on children's education and health outcomes: The case of China. Demographic Research 43(9): 217-244. doi:10.4054/DemRes.2020.43.9.

Liu, C., Lu, L., Zhan, L., Luo, R., Sylvia, S., Medina, A., and Rozelle, S. (2017). Effect of deworming on indices of health, cognition, and education among 25 schoolchildren in rural China: A cluster-randomized controlled trial. American Journal of Tropical Medicine and Hygiene 96(6): 1478-1489.

Loken, K.V. (2010). Family income and children's education: Using the Norwegian oil boom as a natural experiment. Labour Economics 17: 118-129. doi:10.1016/ j.labeco.2009.06.002.

Lu, Y. (2012). Education of children left behind in rural China. Journal of Marriage and the Family 74(2): 328-341. doi:10.1111/j.1741-3737.2011.00951.x.

Martens, L, Southerton, D., and Scott, S. (2004). Bringing children (and parents) into the sociology of consumption. Journal of Consumer Culture 4(2): 155-182. doi:10.1177/1469540504043680.

Meng, X. and Yamauchi, C. (2017). Children of migrants: The cumulative impact of parental migration on children's education and health outcomes in China. Demography 54(5): 1677-1714. doi:10.1007/s13524-017-0613-z.

Nie, J., Pang, X., Wang, L., Rozelle, S., and Sylvia, S. (2020). Seeing is believing: Experimental evidence on the impact of eyeglasses on academic performance, aspirations and dropout among junior high school students in rural China. 
$X u$ et al:: Introduction to the special collection on life-course decisions of families in China

Economic Development and Cultural Change 68(2): 335-355. doi:10.1086/ 700631.

Qin, M., Falkingham, J., Evandrou, M., and Vlachantoni, A. (2020). Attitudes and preferences towards future old-age support amongst tomorrow's elders in China. Demographic Research 43(11): 285-314. doi:10.4054/DemRes.2020.43.11.

Ren, Q. and Treiman, D. (2016). The consequences of parental labor migration in China for children's emotional wellbeing. Social Science Research 58: 46-67. doi:10.1016/j.ssresearch.2016.03.003.

Shi, J., Xu, B., and Wei, Y. (2020). Life-course and cohort effects on Chinese parents' investments in their children. Demographic Research 43(8): 183-216. doi:10.4054/DemRes.2020.43.8.

Tong, Y., Luo, W., and Piotrowski, M. (2015). The association between parental migration and childhood illness in rural China. European Journal of Population 31(5): 561-586. doi:10.1007/s10680-015-9355-Z.

Treas, J. and Chen, J. (2000). Living arrangements, income pooling, and the life course in urban Chinese families. Research on Aging 22(3): 238-261. doi:10.1177/ 0164027500223002 .

Wang, H., Huang, J.Y., and Yang, Q. (2019). Assessing the financial sustainability of the pension plan in China: The role of fertility policy adjustment and retirement delay. Sustainability 11(883): 1-20. doi:10.3390/su11030883.

Wang, L., Li, M., Abbey, C., and Rozelle, S. (2018). Human capital and the middle income trap: How many of China's youth are going to high school? The Developing Economies 56(2): 82-103. doi:10.1111/deve.12165.

Wen, M. and Lin, D. (2011). Child development in rural China: Children left behind by their migrant parents and children of nonmigrant families. Child Development 83(1): 120-136. doi:10.1111/j.1467-8624.2011.01698.x.

Whyte, M.K. (2012). China's post-socialist inequality. Current History 111(746): 229234. doi:10.1525/curh.2012.111.746.229.

Xie, Y. (2013). Gender and family in contemporary China. PSC Research Report No. 13-808.

$\mathrm{Xu}, \mathrm{H}$. and Xie, Y. (2015). The causal effects of rural-to-urban migration on children's well-being in China. European Sociological Review 31(4): 502-519. doi:10.1093/esr/jcv009. 
Yu, J. and Xie, Y. (2015). Cohabitation in China: Trends and determinants. Population and Development Review 41(4): 607-628. doi:10.1111/j.1728-4457.2015. 00087.x.

Zeng, Y. (1991). Family dynamics in China: A life table analysis. Madison: The University of Wisconsin Press.

Zhan, L., Zhang, J., and Lu, C. (2020). The long-run effects of poverty alleviation resettlement on children development with gender gap: Evidence from a natural experiment in China. Demographic Research 43(10): 245-284. doi:10.4054/DemRes.2020.43.10.

Zhang, H., Behrman, J., Fan, C., Wei, X., and Zhang, J. (2014). Does parental absence reduce cognitive achievements? Evidence from rural China. Journal of Development Economics 111: 181-195. doi:10.1016/j.jdeveco.2014.09.004.

Zhou, H., Ye, R., Sylvia, S., Rose, N., and Rozelle, S. (2020). We can see the future at three: Cognitive skills and the life cycle of rural Chinese children. Demographic Research 43(7): 169-182. doi:10.4054/DemRes.2020.43.7.

Zhou, X. and Hou, L. (1999). Children of the cultural revolution: The state and the life course in the People's Republic of China. American Sociological Review 64(1): 12-36. doi:10.2307/2657275.

Zhou, X., Tuma, N.B., and Moen, P. (1996). Stratification dynamics under state socialism: The case of urban China, 1949-1993. Social Forces 74(3): 759-796. doi: $10.2307 / 2580381$. 
$X u$ et al:: Introduction to the special collection on life-course decisions of families in China 